\title{
VIABILIDADE ECONÔMICA DO USO DO BIOGÁS COMO COMBUSTÍVEL VEICULAR EM UMA GRANDE PROPRIEDADE RURAL
}

Economic viability of the use of biogas for mobility in a big farm DOI: 10.48075/igepec.v25i1.25428

Pedro Höfig

Janaina Camile Pasqual Lofhagen

Glauco Marighella Ferreira da Silva 


\title{
VIABILIDADE ECONÔMICA DO USO DO BIOGÁS COMO COMBUSTÍVEL VEICULAR EM UMA GRANDE PROPRIEDADE RURAL
}

\author{
Economic viability of the use of biogas for mobility in a big farm
}

DOI: $10.48075 /$ igepec.v25i1.25428

\author{
Pedro Höfig \\ Janaina Camile Pasqual Lofhagen \\ Glauco Marighella Ferreira da Silva
}

\begin{abstract}
Resumo: Este trabalho objetivou analisar se é viável economicamente utilizar o biogás como combustível veicular para abastecer a frota da fazenda Córrego Azul, localizada em Brasilândia, no Mato Grosso do Sul. Foram prospectados três cenários, nos quais alteram-se essencialmente a produção de biogás e a distância de seu transporte. No primeiro cenário, utilizou-se biogás de duas granjas da fazenda, que contém 2 biodigestores, e foi encaminhado via gasoduto até o microposto. No segundo cenário, considerou-se o biogás de apenas uma granja, que contém 1 biodigestor, e foi encaminhado ao mesmo local. No terceiro cenário, foi considerado o microposto próximo a um biodigestor. Todos cenários apresentaram Valor Presente Líquido e o Valor Presente Líquido Anualizados positivos, mas apenas o último cenário apresentou Taxa Interna de Retorno acima da taxa mínima de atratividade, demonstrando ser o cenário mais interessante para investimento.

Palavras-chave: Agronegócio. Biometano. Sustentabilidade. Energia. Suinocultura. Resíduos agropecuários.

Abstract: This work aimed to analyze whether it is economically viable to use biogas as a vehicle fuel to supply a fleet of the Córrego Azul farm, located in Brasilândia, Mato Grosso do Sul-Brazil. Three scenarios were explored, in which the production of biogas and distance from its transportation were altered. In the first scenario, the biogas produced in two facilities on the farm were used, which comprise 2 biodigesters, and was sent via pipeline to the biomethane filling micro-station. In the second scenario, the biogas from only one facility was considered, which contains 1 biodigester, and was sent to the same location. In the third scenario, the micro-station was considered close to a biodigester. All scenarios presented positive Net Present Value and Annual Net Present Value, but only the last scenario presented the Internal Rate of Return above the minimum attractiveness rate, demonstrating the most interesting scenario for investment.
\end{abstract}

Keywords: Agribusiness. Biomethane. Sustainability. Energy; Pig production. Agricultural waste.

Resumén: Este trabajo tuvo como objetivo analizar si es económicamente viable utilizar biogás como combustible vehicular para abastecer la flota de la finca Córrego Azul, ubicada en Brasilândia, Mato Grosso do Sul - Brasil. Se exploraron tres escenarios, en los cuales la producción de biogás y distancia de su transporte fueron alteradas. En el primer escenario, se utilizó biogás de dos unidades de la finca, que contiene 2 biodigestores, y se envió vía gasoducto al microposto. En el segundo escenario, se consideró el biogás de una sola unidad, que contiene 1 biodigestor, y se envió a la misma ubicación. En el tercer escenario se consideró el microposto cercana a un biodigestor. Todos los escenarios presentaron Valor Presente Neto y Valor Presente Neto Anual positivos, pero solo el último escenario presentó una Tasa Interna de Retorno (TIR) por encima de la tasa mínima de atractivo, resultando ser el escenario más interesante para inversión.

Palabras clave: Agronegocio. Biometano. Sostenibilidad. Energía. Cría de cerdos. Resíduos agropecuarios. 
Informe GEPEC, ISSN:1679-415X, Toledo, V. 25, n.1, p. 185-202, jan./jun. 2021. 


\section{INTRODUÇÃO}

A busca pela sustentabilidade nos sistemas produtivos passa pela valorização dos resíduos orgânicos de origem animal e vegetal. Ao se considerar os resíduos como insumos, uma série de possibilidades de valorização converge para os mesmos objetivos: a diminuição dos custos, a adequação ambiental e a qualificação do trabalho humano. Neste sentido, quando resíduos orgânicos são submetidos ao processo de digestão anaeróbia visando sua estabilização para controlar problemas ambientais, um dos produtos criados é o biogás (Drosg et al., 2015).

O biogás tem sua origem em decomposições da matéria orgânica que ocorrem na ausência de oxigênio. A substância orgânica é convertida em biogás por bactérias em várias etapas nos biodigestores. As principais aplicações energéticas do biogás são a energia térmica, energia elétrica e a mobilidade (Bley-Júnior et al., 2009).

O biometano, resultante do refino do biogás, é um gás combustível renovável e limpo, de propriedades físicas e composição química idênticas ao gás natural, o que lhe confere condições técnicas de substituir o gás de origem fóssil em todas as aplicações e segmentos de consumo (ABIOGÁS, 2018).

O Brasil, desde os primórdios de sua história, demonstra que possui um gigantesco potencial econômico no setor do agronegócio. Todavia, por mais incomum que pareça, por meio do gerenciamento de resíduos, os espaços rurais podem incorporar outras vocações que não seja a produção de alimentos. Para tanto, basta ver em algum excedente de sua produção uma reutilização. O biogás, contudo, é subvalorizado pelo planejamento energético nacional, tendo em vista a tradicional pequena escala de produção. Ignora-se, entretanto, o fato de ser um produto versátil, o que pode criar uma nova dimensão econômica, tornando-se uma nova parte da economia rural (Bley-Júnior, 2015).

Um dos principais fundamentos do uso do biogás e do biometano é a promoção de uma sinergia entre o tratamento de resíduos e a geração de um produto. A vertente ambiental impacta diretamente o setor agropecuário, uma vez que o tratamento adequado de resíduos permite um melhor uso da terra e expande o potencial para a criação de animais, além de demonstrar a oportunidade de mudança de matriz de combustível das frotas de veículos pesados de diesel para biometano.

O desenvolvimento de uma cadeia descentralizada de biocombustível estimulará a inteligência técnica potencialmente aplicada no planejamento e projetos, a mão de obra especializada em montagem e manutenção de biorrefinarias e beneficiará a indústria de processos de produção, como biodigestores e outros componentes, assim como, e de maneira especial, a indústria automotiva, cujos produtos movidos a biometano só não são oferecidos ao mercado brasileiro por não encontrarem aqui as necessárias soluções de oferta descentralizada de biometano (ABIOGÁS, 2018).

Para purificar o biogás em biometano e usá-lo como combustível veicular, existe a necessidade de remoção de alguns de seus componentes, tais como: umidade, ácido sulfídrico (H2S), dióxido de carbono (CO2) e partículas (ADNETT, 200o), o que exige investimento em mais uma etapa de processamento após a produção do biogás. De acordo com a ANP (Agência Nacional de Petróleo) na Portaria no 8 de 30 de janeiro de 2015, o biometano é um biocombustível gasoso constituído essencialmente de metano, derivado da purificação do biogás. Segundo a ANP, com a resolução no 685 aprovada no dia 9 de junho de 2017, a porcentagem mínima de metano no gás natural para uso veicular deve ser de $90 \%$ e a máxima de $\mathrm{CO}_{2}$ é de $3 \%$. 
Neste sentido, é essencial estudar as alternativas de investimentos e optar pela melhor solução antes de efetuá-los. Os instrumentos que se destacam para calcular a viabilidade econômica consideram descontos de valor ao longo do tempo, numa sucessão de entradas e saídas de caixa (fluxo de caixa). A questão consiste na conversão de uma quantia atual numa série de pagamentos futuros e vice-versa (SENAR/PR, 2014).

A fazenda Córrego Azul, situada em Brasilândia/MS, é produtora de aproximadamente 100 mil suínos e os tratamentos dos dejetos são realizados em seis biodigestores. O potencial de geração de biogás da fazenda é de aproximadamente $6.000 \mathrm{~m}^{3} /$ dia.

Atualmente, a fazenda utiliza biogás gerado por 4 biodigestores, o que representa uma produção aproximada de $4.600 \mathrm{~m}^{3} /$ dia. O biogás tratado é transportado por $10 \mathrm{~km}$ de gasoduto até a minicentral de geração de energia elétrica, com potência instalada de $500 \mathrm{~kW}$. No entanto, dois biodigestores não estão ligados a esta rede de gasoduto e seu biogás não é aproveitado, devido a necessidade de novos investimentos. Esse produto, purificado e convertido em biometano, por meio de uma microbiorrefinaria, pode ser usado no abastecimento veicular da frota desta propriedade rural. Em casos onde isso já acontece, está se verificando que a opção pela produção de biometano agrega até quatro vezes mais valor por metro cúbico de biogás produzido do que aquele utilizado na energia elétrica (ABIOGÁS, 2018).

Desta forma, para a opção pela introdução de um novo combustível para mobilidade, originado de uma fonte atualmente desperdiçada, é necessária uma detalhada análise. Para tanto, objetivou-se neste trabalho um estudo de viabilidade econômica do uso de biometano para abastecimento da frota dessa propriedade rural, tendo em vista que a falta de informação pode ser uma das principais barreiras para o desenvolvimento do setor nacional de biogás, já que aumenta a sensação de risco de investidores, financiadores e produtores de biogás.

\section{2 - PROCEDIMENTOS METODOLÓGICOS}

A área de estudo, denominada fazenda Córrego Azul, situa-se no município de Brasilândia/MS e dista aproximadamente $350 \mathrm{~km}$ da capital do estado, Campo Grande, e 730 km de São Paulo.

O clima local, de acordo com a classificação de Köppen, é denominado como Aw, isto é, clima tropical do Brasil central com um a três meses secos (Mendonça \& DanniOliveira, 2007). O clima quente na maior parte do ano favorece a produção de biogás; nos dias mais frios do inverno observa-se grande queda na produção desse produto.

A vegetação natural é classificada como Cerrado (Conti \& Furlan, 2008). A vegetação remanescente é a do cerradão, mas verifica-se em alguns locais faixas de transição de mata atlântica, assim como constatado por Ab’Sáber (2003).

Embora existam inúmeros estudos nos quais se tem informações referentes à cálculos de produção de biogás tendo como matéria prima o dejeto de suínos, como Kunz e Oliveira (2006), optou-se por utilizar dados primários, já que se trata de um produto que tem sua produção alterada de acordo com a realidade local. Isto é, a propriedade já possui quatro biodigestores onde já se mede a produção de biogás e, neste caso, ocorre a produção diária de $0,1 \mathrm{~m}^{3}$ de biogás/cabeça de suíno em terminação e $0,2 \mathrm{~m}^{3}$ biogás/cabeça matriz.

$\mathrm{O}$ estudo de mercado combinado à engenharia do projeto permitiu gerar os fluxos de caixa dos cenários propostos (Anexos 1, 2 e 3). Os indicadores utilizados foram o VPL, o VPLa, o Payback e a TIR. 
A viabilidade econômica consiste em identificar se os saldos líquidos acumulados do projeto são positivos ao longo do tempo. Geralmente, um investimento só deve ser feito se ele gerar resultados maiores do que uma aplicação alternativa (Peres et al., 2010).

O Valor Presente Líquido (VPL), o Valor Presente Líquido Anualizado (VPLa), o Payback e a Taxa Interna de Retorno (TIR) são métodos conhecidos e utilizados para a análise de viabilidade econômica e que auxiliam o processo de tomada de decisão.

O VPL é a diferença do valor presente das receitas menos o valor presente dos custos (Silva \& Fontes, 2005), descontado a taxa de juros determinada pelo mercado ou mesmo aquela implementada pelo governo com taxas subsidiadas (SENAR/PR, 2014), expressado por:

$$
V P L=\sum_{t=1}^{n} \frac{F C_{t}}{(1+i)^{t}}
$$

Em que FC é o fluxo de caixa naquele período, t é a quantidade de tempo que o dinheiro foi investido no projeto, i é a taxa de desconto e n é a duração do projeto.

Já o VPLa transforma o valor atual do projeto ou o seu VPL em fluxo de receitas ou custos periódicos e contínuos, equivalentes ao valor atual, durante a vida útil do projeto (Silva \& Fontes, 2005), utilizado em comparações entre atividades com diferentes períodos de produção (SENAR/PR, 2014), dado por:

$$
V P L a=V P L\left(\frac{i(1+i)^{n}}{(1+i)^{n}-1}\right)
$$

A TIR é a taxa de desconto que iguala o valor atual das receitas futuras ao valor atual dos custos futuros do projeto, constituindo uma medida relativa que reflete o aumento no valor do investimento ao longo do tempo, com base nos recursos requeridos para produzir o fluxo de receitas (Silva et al., 2002). Matematicamente, a TIR é a taxa $\left(\mathrm{j}^{*}\right)$ que torna o valor presente líquido do projeto igual a zero (Lapponi, 2000):

$$
0=-I+\sum_{t=1}^{n} \frac{F C_{t}}{\left(1+j^{*}\right)}
$$

O Payback é um dos métodos mais simples: consiste, basicamente, em determinar o número de períodos necessários para recuperar o capital investido (Nogueira, 1997). Isto é, o tempo necessário para que o somatório das parcelas anuais seja igual ao investimento inicial (Casarotto-Filho \& Kopittke, 1994). Assim, quanto maior for o Payback, mais incerta será a recuperação do capital investido.

Para os custos de implantação do projeto de uso do biogás como fonte combustível veicular foram empregados dados levantados com fornecedores e informações já existentes na propriedade, sendo que não foi considerado o investimento nos biodigestores, uma vez que, por questões de legislação, eles já existem na propriedade independente deste projeto. Os custos operacionais do microposto foi informado pelo fornecedor, enquanto o valor de investimento no sistema de transporte e armazenamento de biogás já se encontra no histórico da propriedade.

Além disso, foram calculadas as variações das estimativas de receitas e despesas ao longo deste período. Segundo a ANP (2015), o biometano produzido a partir de produtos e resíduos pecuários, agrícolas e agroindustriais deve ser tratado de maneira análoga ao gás natural veicular (GNV), inclusive em termos de valoração econômica e usos, desde que atenda às especificações técnicas da ANP no $08 / 2015$. Sendo assim, como receita, foi calculado o preço médio do $\mathrm{m}^{3}$ de GNV em Três Lagoas/MS em

Informe GEPEC, ISSN:1679-415X, Toledo, v. 25, n.1, p. 185-202, jan./jun. 2021. 
outubro de 2018 (ANP, 2018); como despesas, foram consideradas os custos operacionais do microposto, onde se refina o biogás e se realiza o abastecimento.

A viabilidade de longo prazo para o projeto foi realizada para um período de 10 anos. No caso dos investimentos, foi considerada a pressuposição de que os principais desembolsos foram feitos no ano zero, como se fossem dispendidos os recursos necessários aos processos produtivos de uma só vez. Por simetria, foi vendido todo o estoque de capital inicial da empresa no final do último ano do horizonte considerado (Höfig, Höfig \& Dossa, 2018).

No tocante ao capital físico, foi adaptado à metodologia da CONAB (2010). Assim, foram depreciadas todas máquinas e equipamentos em 15 anos, com valor residual de $20 \%$.

Foram prospectados três cenários, nos quais alteram-se essencialmente a produção de biogás e a distância de seu transporte (Figura 1). No primeiro cenário, utilizou-se biogás de duas granjas e o levou até a oficina da fazenda. No segundo cenário, usou-se biogás de apenas um biodigestor e o levou até o mesmo local. No terceiro cenário, levou-se o refinador até um biodigestor.

Figura 1 - Mapas dos cenários prospectados
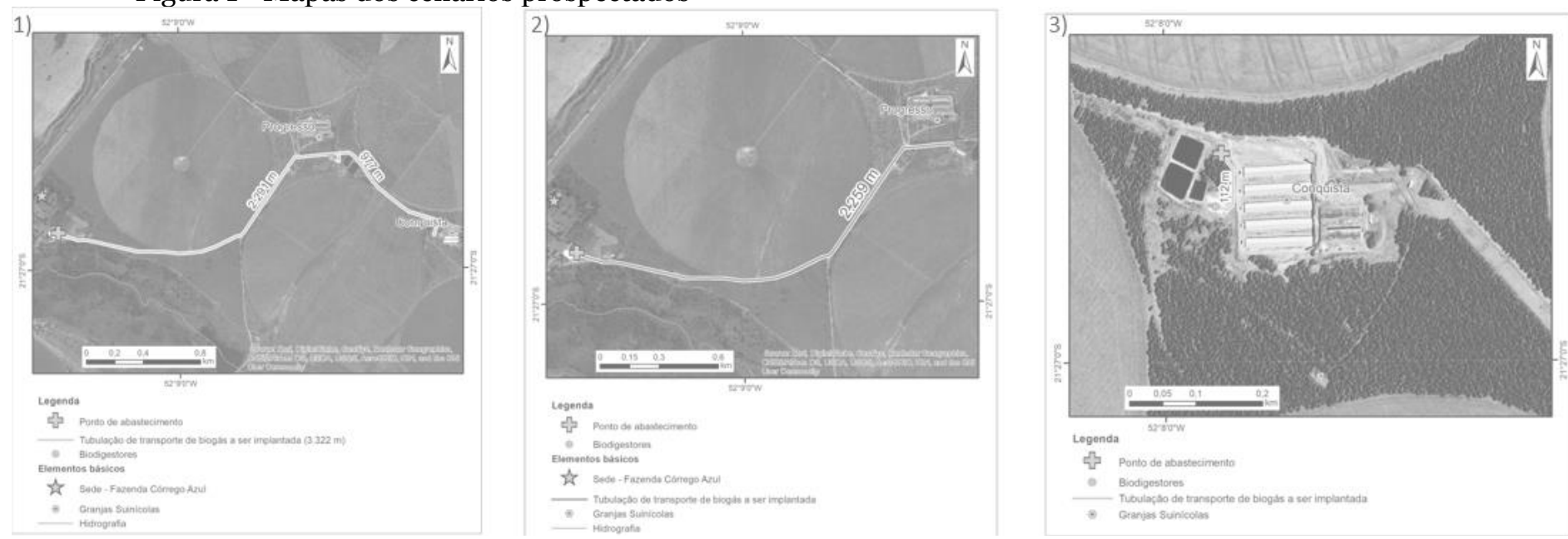

As análises de viabilidade foram realizadas a partir dos valores de fluxo de caixa do projeto. A taxa de juros escolhida foi a de 7,5\%, a mesma existente para investimento no programa de Agricultura de Baixo Carbono (ABC) do plano agrícola da safra (MAPA, 2017). Com isso, tal taxa foi definida como a Taxa Mínima de Atratividade, na qual se baseou para avaliação de retorno e atratividade em projetos de investimento (Casarotto-Filho, 2002).

Com o VPL e VPLa do projeto, foi encontrada a viabilidade econômica. Isto é, foi comparado o modo como projeto desenvolve suas atividades com o fluxo de caixa com um rendimento líquido de $7,5 \%$. Com a TIR foi verificado se a rentabilidade patrimonial do projeto é abaixo ou acima do custo de oportunidade do capital para o empresário, entendendo que o custo de oportunidade são as remunerações que são descartadas para a realização do investimento. Já com o Payback apurou-se o número de períodos necessários para recuperar o capital investido. 


\section{3 - RESULTADOS E DISCUSSÃO}

Sendo parte das granjas que compõem a Fazenda Córrego Azul, as granjas Conquista, com 9.087 animais em terminação, e Progresso, com 2.448 matrizes, possuem potencial de produção de $1.398 \mathrm{~m}^{3} /$ dia de biogás (Error! Reference source not found.). Considerando um biogás com $65 \%$ de metano e a necessidade de se atingir 96,5\% deste gás, haveria o potencial de produção diária de 839 $\mathrm{m}^{3} /$ biometano.

Considerou-se como investimento um valor médio de $\mathrm{R} \$ 5.000 / \mathrm{kit}$ GNV/veículo, englobando sete carros, cinco motos, três caminhões e um trator. Para o sistema de transporte e armazenamento de gás, foi considerado o valor de $\mathrm{R} \$$ $65.000 / \mathrm{km}$ de gasoduto. O investimento conjecturado no microposto foi de $\mathrm{R} \$ 150.000,00$, seu custo operacional foi de $\mathrm{R} \$ 0,60 / \mathrm{m}^{3}$ de biometano produzido e, a receita, de $\mathrm{R} \$ 2,79 / \mathrm{m}^{3}$ de biometano gerado. O uso do biometano como combustível veicular poderia evitar um custo de $\mathrm{R} \$ 100 \mathrm{mil} /$ ano, tendo em vista o rendimento desse produto e as despesas apontadas com gasolina e óleo diesel no demonstrativo de resultado operacional da fazenda do ano 2017/2018.

Tabela 1 - Potencial de Produção de Biogás e biometano

\begin{tabular}{lccc}
\hline \multirow{2}{*}{ Unidade } & \multicolumn{2}{c}{ Potencial de produção de biogás (m3) } \\
\cline { 2 - 3 } & Diário & Mensal & Anual \\
\hline Conquista & 908,7 & $27.261,0$ & $331.675,5$ \\
Progresso & 489,6 & $14.688,0$ & $178.704,0$ \\
\hline Total Biogás & 1398,3 & $41.949,0$ & $510.379,5$ \\
\hline Total Biometano $\left(\mathrm{m}^{3}\right)$ & 839,0 & $25.169,4$ & $306.227,7$
\end{tabular}

Fonte: os autores.

No Cenário 1, para o sistema de transporte e armazenamento de biogás contemplou-se $3322 \mathrm{~m}$ de tubulação de polietileno de alta densidade (PEAD), dois sopradores, um abrigo para cada uma dessas máquinas, um gasômetro, além de medidores de vazão e outros acessórios, totalizando o investimento de $\mathrm{R} \$ \mathbf{2 1 5} .930,00$ para levar o biogás até a oficina agrícola da fazenda. Vale ressaltar que as informações referentes aos investimentos e custos operacionais foram levantadas juntos aos fornecedores e também baseadas na experiência do sistema de transporte de gás já existente na propriedade, uma vez que o detalhamento técnico não constitui objetivo deste estudo, porém é fundamental o dimensionamento dos custos e receitas imprescindíveis na análise econômica.

A velocidade de abastecimento direto no veículo é de $6,2 \mathrm{~m}^{3} / \mathrm{h}$ e o rendimento médio por veículo é de $13,8 \mathrm{~km} / \mathrm{m}^{3}$. Portanto, tal velocidade de abastecimento limitaria o consumo diário para apenas 49,6 $\mathrm{m}^{3}$ de biometano, considerando oito horas diárias de abastecimento. Sendo assim, este deve ser o valor de produção de biometano a ser estimado, oferecendo receita anual aproximada de $\mathrm{R} \$ 50.510,16$ e despesa operacional de $\mathrm{R} \$ 10.862,40$.

Contudo, tal realidade de limitação de abastecimento de biometano alterou a dinâmica do projeto: não faz sentido tamanha produção de biogás para gerar no máximo 49,6 m³/biometano/dia. Trata-se de uma situação de como se a oferta de

Informe GEPEC, ISSN:1679-415X, Toledo, v. 25, n.1, p. 185-202, jan./jun. 2021. 
biogás fosse maior que a demanda. A primeira solução seria encontrar outro sistema de refinamento e abastecimento que se conseguisse abastecer maior quantidade por dia, mas outros produtos são extremamente caros, distantes da realidade de uma propriedade rural. Ainda assim, com esta realidade de abastecimento, o negócio pode ser visto como viável economicamente, com um Valor Presente Líquido (VPL) de R\$ 147.579,78, Valor Presente Líquido Anualizado (VPLa) de R\$21.500,30 e Payback de 7,38 anos.

Sendo assim, o VPL maior que zero indicou que o projeto é economicamente viável, já que seus ganhos foram maiores que o investimento necessário para implantálo (Casarotto-Filho \& Kopittke, 1994). Se o VPL é maior do que zero, deve-se aceitar o projeto, ou seja, a empresa vai obter um resultado maior do que seu custo de capital; mas, se o VPL é menor do que zero, o projeto deverá ser rejeitado, ou seja, o retorno do investimento é inferior ao mínimo esperado (Gitman, 2001). O VPLa tem a mesma interpretação do VPL e representa o ganho do negócio distribuído em valores equivalentes anuais.

No entanto, a deficiência comum do VPL e do VPLa, para expressar o retorno do investimento, reside no fato de ambos o expressarem em valores monetários absolutos e não em valores relativos, como é usual no mercado (Kreuz, Souza \& Clemente, 2008). A Taxa Interna de Retorno (TIR) de apenas 5\%, abaixo da taxa mínima de atratividade considerada $(7,5 \%)$, pode sugerir que o negócio não deve ser considerado. A TIR é uma taxa de desconto hipotética que, quando aplicada a um fluxo de caixa, faz com que os valores de despesas, trazidos ao valor presente, sejam iguais aos valores dos retornos dos investimentos, também trazidos ao valor presente. A regra de decisão sugere que a taxa obtida deve ser maior que as taxas de juros do mercado financeiro para o mercado agrícola (Ross, Westerfield \& Jaffe, 1995). Alguns autores sugerem que os investimentos devem ser considerados rentáveis e passíveis de análise apenas se a TIR for maior que a taxa mínima de atratividade (Casarotto-Filho \& Kopittke, 1994; Souza \& Clemente, 1997).

Neste sentido, buscou-se um novo modelo de negócio: considerou-se apenas a granja Progresso como produtora de biogás. Assim, no Cenário 2, o investimento com o sistema de transporte e armazenamento de biogás, para levar o biogás até a oficina agrícola da fazenda, diminuiria para $\mathrm{R} \$ 146.835,00$. Os outros investimentos, bem como as despesas e as receitas, não se alterariam, já que apenas esta unidade suinícola é capaz de produzir $294 \mathrm{~m}^{3} /$ biometano/dia, isto é, muito além do limite de 49,6 $\mathrm{m}^{3}$ /biometano/dia de abastecimento. Com esta realidade, os indicadores de viabilidade econômica foram mais positivos. Porém, a TIR encontrada, que expressa valor relativo, foi de $7 \%$, ainda menor que o custo de oportunidade ou taxa mínima de atratividade escolhida.

Com isso, no Cenário 3, notou-se que, economicamente, o melhor para rentabilidade patrimonial do projeto seria a instalação do microposto ao lado do biodigestor da granja Conquista, o que diminuiria o investimento com o sistema de transporte e armazenamento de gás para apenas $\mathrm{R} \$ 7.280,00$. O operacional da fazenda, contudo, seria diretamente afetado, já que toda a equipe de campo se situa na oficina agrícola da propriedade. Com esta realidade, os indicadores de viabilidade econômica foram os melhores.

Portanto, a comparação do modo como a empresa desenvolverá suas atividades com o fluxo de caixa com um rendimento líquido de $7,5 \%$ revelou a viabilidade do negócio (Tabela ). Leva-se ao entendimento de que produzir e utilizar biometano é uma atividade rentável para propriedades que usam com eficiência as inovações e as tecnologias mais apropriadas. 
Tabela 2 - Indicadores econômicos para os três cenários propostos

\begin{tabular}{llll}
\hline \multicolumn{1}{c}{ Indicador } & \multicolumn{3}{c}{ Valores } \\
\cline { 3 - 5 } \cline { 3 - 5 } VPL & Cenário 1 & Cenário 2 & Cenário 3 \\
VPLa & $\mathrm{R} \$ 147.579,78$ & $\mathrm{R} \$ 181.859,47$ & $\mathrm{R} \$ 251.096,06$ \\
TIR & $\mathrm{R} \$ 21.500,30$ & $\mathrm{R} \$ 26.494,37$ & $\mathrm{R} \$ 36.581,16$ \\
Taxa mínima de atratividade & $5 \%$ & $7 \%$ & $14 \%$ \\
Payback & $7,50 \%$ & $7,50 \%$ & $7,50 \%$ \\
\hline Fluxo médio & 7,38 & 6,58 & 4,53 \\
\hline Fyynn
\end{tabular}

Fonte: os autores.

Baseado na TIR de $14 \%$ e com a taxa mínima de atratividade de 7,5\%, infere-se que a produção de biometano nestas circunstâncias é um negócio rentável. Ou seja, se verificou que o negócio tem capacidade de se pagar e usar o biometano para mobilidade pode ter um melhor custo de oportunidade do que a aplicação do investimento no mercado financeiro. Esta TIR é semelhante a encontrada por Gomes e Piacenti (2016), em estudo realizado na bacia do Lajeado Grande, região de Toledo/PR, envolvendo um projeto de biogás para combustível veicular, oriundo de aves, bovinos e suínos de diversas propriedades familiares e $34,5 \mathrm{~km}$ de biogasoduto. Neste trabalho, porém, a velocidade de abastecimento não foi considerada um fator limitante na receita.

Entretanto, nota-se que, em nosso estudo, o ideal seria aproveitar toda a produção de biogás destas granjas suinícolas. Esse produto deve ser utilizado de alguma outra forma, como energia térmica ou elétrica. Esta análise, todavia, foge do escopo deste trabalho, mas sabe-se que em uma situação onde a oferta é maior que a demanda interna, a comercialização para terceiros é o melhor caminho. Neste sentido, concordando com Leitão e Silva (2018), o tempo de retorno do investimento em projetos de biogás torna-se atrativo com a intensificação do uso do sistema.

Em suas pesquisas, Coldebella, Souza, Ferri e Kolling (2008) e Cervi, Esperancini e Bueno (2010) demonstram que o sistema de produção de biogás é potencialmente viável do ponto de vista econômico. Ressalta-se, porém, a dificuldade de se comparar projetos com montantes de investimentos distintos. Além disso, existe dificuldade de se encontrar estudos brasileiros de viabilidade econômica para uso do biogás como combustível veicular. Em contrapartida, há alguma diversidade de trabalhos sobre a utilização deste produto para geração de energia elétrica.

No entanto, nestes estudos não se usam a TIR como indicador de viabilidade e nem o VPLa; apenas VPL e Payback, como os estudos de Esperancini, Colen, Bueno, Pimentel e Simon (2007), Souza, Pereira, Nogueira, Pavan e Sordi (2004) e Martins e Oliveira (2011). Não é adequado comparar valores de VPL. Com este indicador, projetos grandes, que envolvem um grande montante de investimento inicial, tendem a apresentar um VPL superior a projetos menores, mesmo que estes projetos grandes não sejam necessariamente melhores em termos relativos. Ademais, o biogás é um produto que permite diversos arranjos tecnológicos e financeiros, de acordo com a realidade local, o que dificulta as comparações.

Esperancini et al. (2007) avaliaram o uso do biogás produzido pelos dejetos de suínos na substituição de fontes de energia em um assentamento rural. No uso

Informe GEPEC, ISSN:1679-415X, Toledo, v. 25, n.1, p. 185-202, jan./jun. 2021. 
domiciliar, o biogás foi aproveitado como gás de cozinha, aquecimento de água e iluminação. A recuperação do investimento ocorreu em 2,5 anos. Na produção, a energia foi utilizada em distintos equipamentos e o investimento foi recuperado em 11 meses.

Souza et al. (2004) concluíram que a viabilidade do sistema de geração energia com uso de biogás da suinocultura depende da tarifa e da demanda. Com a tarifa de R\$ 190,o0 $\mathrm{MWh}^{-1}$, o tempo de recuperação do investimento, considerando o desconto da taxa de juros, foi de 5 anos. Martins e Oliveira (2011) chegaram a valores de 26 a 104 meses de retorno do investimento para geração de energia elétrica a partir do biogás da suinocultura, de acordo a variação na tarifa de energia e no modelo de negócio escolhido.

Destaca-se, ainda, que, em todo caso, uma nova alternativa, para ser utilizada pelo produtor, deve trazer, necessariamente, algumas vantagens adicionais em relação àquelas em uso. Em geral, espera-se que, entre estas, encontre-se a econômica. Mas esta, sendo uma condição necessária, não é suficiente. Neste enfoque é necessário que cada nova alternativa, antes de ser difundida, deva ser analisada em um contexto envolvendo aspectos técnicos, econômicos, sociais e familiares. Logo, fica evidente que uma nova proposta a ser apresentada para os produtores rurais não deve ser encaminhada somente com base em critérios quantitativos.

É necessário, portanto, avaliar também os critérios qualitativos que caracterizam objetivos implícitos dos produtores rurais. A melhor decisão a ser adotada é aquela que apresenta o mais alto retorno financeiro; existem, contudo, muitas outras situações em que os aspectos econômicos financeiros não são os mais relevantes. A decisão é tomada em função de critérios considerados subjetivos, mas que são, de qualquer forma, relevantes (Dossa, 2000).

Neste sentido, a operacionalização do sistema, a segurança energética e autossuficiência da propriedade ganham peso. Consumir o que se produz resulta em menos desperdícios e maior eficiência. Essas questões não entram na conta dos indicadores econômicos, mas, com certeza, são contabilizadas na hora de se tomar a decisão de investir ou não investir.

A possibilidade de se mobilizar recursos energéticos locais que complementem os sistemas centrais oferece longevidade aos grandes sistemas baseados na centralização e determina novos arranjos produtivos locais, tornando-se uma ferramenta de inclusão social. E isso não só se fundamenta nos custos crescentes determinados pelas perdas físicas e econômicas dos grandes sistemas, mas também na necessidade imperiosa de se estabelecer a redução de impactos ambientais relacionados com as formas de produzir e usar energias, que tendem a utilizar fontes fósseis emissoras de gases do efeito estufa.

Nota-se com isso que, o biodigestor, além de produzir gás, reduz o potencial poluidor dos resíduos de uma propriedade agrícola e gera fertilizantes. Por isso, é considerado por alguns como poço de petróleo, uma fábrica de fertilizantes e uma usina de saneamento, unidos em um mesmo equipamento (Barreira, 2011).

\section{CONSIDERAÇÕES FINAIS}

Após a análise dos resultados obtidos nesse estudo, verificou-se que em todos cenários considerados, a receita não se altera, já que o alcance de abastecimento diário de biometano, devido à velocidade, é um fator limitante.

Em um cenário onde se utiliza o biogás das duas granjas e, por isso, se tem um maior investimento com o sistema de transporte e armazenamento de biogás, o Valor Presente Líquido (VPL) e o Valor Presente Líquido Anualizados (VPLa) são positivos,

Informe GEPEC, ISSN:1679-415X, Toledo, v. 25, n.1, p. 185-202, jan./jun. 2021. 
mas a Taxa Interna de Retorno (TIR) ficou abaixo da taxa mínima de atratividade. Já em uma situação na qual se usa apenas o biogás da granja Progresso, o VPL e o VPLa são ainda mais positivos e a TIR ficou mais próxima do custo de oportunidade considerado.

Entretanto, no caso de se instalar o sistema de refinamento do biogás e abastecimento dos veículos ao lado do biodigestor da granja Conquista, todos indicadores melhoram e a TIR fica acima da taxa mínima de atratividade, o que indica ser a melhor escolha para rentabilidade patrimonial do projeto. Contudo, embora esta seja a melhor escolha econômica, isso dificultaria o operacional da fazenda, pois toda a equipe de campo situa-se em sua oficina agrícola.

Ademais, concluiu-se que existem outros fatores que não entram na conta da viabilidade econômica, mas são considerados na tomada de decisão do produtor rural, como a segurança energética à fazenda, reduzindo prejuízos por eventuais quedas ou falta de energia, e autossuficiência da fazenda, promovendo a substituição do uso de combustíveis fósseis a base de petróleo, como diesel ou gasolina. Esses dois fatores são essenciais para auxiliar na tomada de decisão e representam um grande diferencial do biogás como fonte de energia.

Para um setor rural rentável e permanente, é essencial que se use um combustível intrínseco deste setor, isto é, um combustível que é parte integrante de seu sistema de produção.

\section{REFERÊNCIAS}

AB'SÁBER, A. N. Os domínios de natureza no Brasil: potencialidades paisagísticas. São Paulo: Ateliê, 2003.

ABIOGÁS - Associação Brasileira de Biogás e do Biometano. Proposta de Programa Nacional de Biogás e do Biometano. São Paulo: ABIOGÁS, 2018.

\section{ADNETT. Anaerobic Digestion of Agro-Industrial Wastes: Information}

Networks. Technical Summary on Gas Treatment. Netherlands, 2000. 31p.

ANP - Agência Nacional do Petróleo. Resolução n 685, de 29 de junho de 2017. $11 p$.

ANP - Agência Nacional do Petróleo. Portaria 8, de 30 de janeiro de 2015. 9p.

ANP - Sistema de Levantamento de Preços. Disponível em:

http://anp.gov.br/preco/prc/Resumo Por Estado Municipio.asp Acesso em 22 de Outubro de 2018.

BARREIRA, P. Biodigestores: energia, fertilidade e saneamento para zona rural. São Paulo: Ícone, 2011.

BLEY-JÚNIOR, C. J. Biogás: a energia invisível. Foz do Iguaçu: Itaipu Binacional, 2015 .

BLEY-JÚNIOR, C. J.; LIBÂNIO, J. C.; CALINKIN, M.; OLIVEIRA, M. M.

Agroenergia da biomassa residual: perspectivas energéticas, socioeconômicas e ambientais. Foz do Iguaçu/ Brasília: Technopolitik Editora, 2009. 
CASAROTTO-FILHO, N.; KOPITTKE, B. H. Análise de investimentos. São Paulo: Editora Atlas S/A, 1994.

CASAROTTO FILHO, N. Projeto de negócio: estratégias e estudos de viabilidade redes de empresas, engenharia simultânea, plano de negócio. São Paulo: Atlas, 2002.

CERVI, R. G.; ESPERANCINI, M. S. T.; BUENO, O. C. Viabilidade econômica da utilização do biogás produzido em granja suinícola para geração de energia elétrica. Engenharia Agrícola, 2010 p. 831-844.

COLDEBELLA, A. SOUZA, S.N.M.; FERRI, P.; KOLLING, E.M. Viabilidade da geração de energia elétrica através de um motor gerador utilizando biogás da suinocultura. Informe Gepec, v. 12, n. 2, 2008.

CONAB. Custo de produção agrícola: a metodologia da Conab. Brasília, 2010.

CONTI, J. B.; FURLAN, S. A. Geoecologia: o clima, os solos e a biota. In: ROSS, J. L. S. (org.). Geografia do Brasil. São Paulo: Editora da Universidade de São Paulo, 2008.

DOSSA, D. A decisão econômica num sistema agroflorestal. Colombo, 2000. (Embrapa Florestas. Circular técnica 39).

DROSG, B.; FUCHS, W.; AL SEADI, T.; MADSEN, M.; LINKE, B. Nutrient Recovery by Biogas Digestate Processing. IEA Bioenergy, ISBN 978-1-91015416-8 (e-book electronic edition),2015. $40 \mathrm{p}$.

ESPERANCINI, M.S.T.; COLEN, F.; BUENO, O. de C.; PIMENTEL, A.E.B.; SIMON, E.J. Viabilidade técnica e econômica da substituição de fontes convencionais de energia por biogás em assentamento rural do Estado de São Paulo. Revista de Engenharia Agrícola, Jaboticabal, v.27, n.1, p.110-118, 2007.

GITMAN, L. J. Princípios de administração financeira. 2 ed. Porto Alegre: Bookman, 2001.

GOMES, A. C. A.; PIACENTI, C. A. A Viabilidade Econômico-Financeira do Biogás para Uso Veicular na Região de Toledo, Paraná, Revista Paranaense de Desenvolvimento, Curitiba: IPARDES, v.37, n.130, p.83-97, jan./jun. 2016.

HÖFIG, P.; HÖFIG, B.; DOSSA, D. Rentabilidade e tomada de decisão em uma fazenda de café irrigado no município de Unaí/MG, Revista de Agronegócios Reagro, v. 7, n. 2, p. 60-77, jul./dez., 2018.

IBGE - Instituto Brasileira de Geografia e Estatística - Disponível em http://geoftp.ibge.gov.br/cartas e mapas/bases cartograficas continuas/. Acesso em 25 de outubro de 2018.

KREUZ, C. L.; SOUZA, A.; CLEMENTE, A. Custo de produção, expectativas de retorno e de riscos do agronegócio mel no planalto norte de Santa Catarina, Custo e @gronegócio online, v. 4, n.1 - jan/abr, 2008. 
KUNZ, A.; OLIVEIRA, P.A.V. Aproveitamento de dejetos animais para geração de biogás. Revista de Política Agrícola, Brasília, v.15, n.3, p.28-35, 2006.

LAPPONI, J.C. Projetos de investimento: construção e avaliação do fluxo de caixa - modelos em Excel. São Paulo, Lapponi, 2000.378p.

LEPSCH, I. F. Formação e Conservação dos Solos. São Paulo: Oficina de Textos, 2002.

LEITÃO, F. O.; SILVA, W. H. da. Geração de energia e renda a partir do tratamento dos resíduos da suinocultura. IGepec, Toledo, v. 22, n.1, p. 116-132, jan./jun. 2018.

MAPA. Plano agrícola e pecuário: 2017/2018. Brasília: BINAGRI: 2017.

MARTINS, F. M.; OLIVEIRA, P. A. V. de. Análise econômica da geração de energia elétrica a partir do biogás na suinocultura, Engenharia Agrícola, Jaboticabal, v.31, n.3, p.477-486, maio/jun. 2011

MENDONÇA, F; DANNI-OLIVEIRA, I. Climatologia: noções básicas e climas do Brasil. São Paulo: Oficina de textos, 2007.

NOGUEIRA, E. Análise de investimentos. In: BATALHA, M. O. (Coord.). Gestão agroindustrial: GEPAI- Grupo de Estudos e Pesquisas Agroindustriais. São Paulo: Atlas, 1997. p.223-288.

PERES, F. C.; HIRONAKA, G. M. F. N.; CANZIANI, J. R.; GUIMARÃES, V. A.; OLIVEIRA, M. M. C. de. O programa empreendedor rural. Curitiba: SEBRAE/PR e SENAR/PR, 2010.

ROSS, S. A.; WESTERFIELD, R. W.; JAFFE, J. F. Administração Financeira. São Paulo: Editora Atlas S/A, 1995.

ROSS, J. L. S. Os fundamentos da Geografia da natureza. In: ROSS, J. L. S. (org). Geografia do Brasil. São Paulo: Editora da Universidade de São Paulo, 2008.

SENAR/PR. Trabalhador na administração de empresas agrosilvipastoris. Gestão Rural volume 1. SENAR/PR, Curitiba, 2014.

SILVA, M. L.; FONTES, A. A. Discussão sobre os critérios de avaliação econômica: Valor Presente Líquido (VPL), Valor Anual Equivalente (VAE) e Valor Esperado da Terra, R. Árvore, Viçosa/MG, v. 29, n.6, p. 931-936, 2005.

SILVA, M. L.; JACOVINE, L. A. G.; VALVERDE, S. R. Economia florestal. Viçosa, MG: Universidade Federal de Viçosa, 2002. 178 p.

SOUZA, A.; CLEMENTE, A. Decisões financeiras e análise de investimentos: fundamentos, técnicas e aplicações. 2.ed. São Paulo: Atlas, 1997. 
SOUZA, S.N.M.; PEREIRA, W.C.; NOGUEIRA, C.E.C.; PAVAN, A.A.; SORDI, A. Custo da eletricidade gerada em conjunto motor-gerador utilizando biogás da suinocultura. Acta Scientiarum Technology, Maringá, v.26, n.2, p.127-133, 2004.

WONG S.; BIOLETTI R. Carbon Dioxide Separation Technologies. Carbon \& Energy Management, Canadá, 14p. 2002.

Submetido em 22/7/2020

Aprovado em 20/12/2020

\section{Sobre o(s) Autor(es):}

\section{Pedro Höfig}

Geógrafo (Universidade Estadual de Londrina - UEL), mestre em Ciência do Solo (Universidade Federal do Rio Grande do Sul), diretor da Catena Planejamento Territorial e agricultor. Email: pedro@catenaterritorial.com

\section{Janaina Camile Pasqual Lofhagen}

Doutora em Gestão Urbana, mestre em Cadastro Técnico Multifinalitário e Gestão Territorial. Graduada em Relações Internacionais em Administração de Empresas. Foi consultora da Fundação Parque Tecnológico Itaipu e do Centro Internacional de Energias Renováveis Biogás (CIBiogás) durante 7 anos, participando da estruturação e implantação de cursos em Energias Renováveis. Foi pesquisadora da Federação das Indústrias do Paraná. É consultora da Organização das Nações Unidas para o Desenvolvimento Industrial (UNIDO) e analista de projetos do GEF Biogás Brasil, um projeto liderado pelo Ministério da Ciência, Tecnologia e Inovações (MCTI) e implementado pela UNIDO. Também é professora na PUC-PR. Tem diversas parcerias nacionais e internacionais relacionadas ao estudo de fontes renováveis de energia, com foco na gestão urbana mais sustentável.

Email: janaina@maxc.com.br

\section{Glaugo Marighella Ferreira da Silva}

Geógrafo (UEL), especialista em Gestão Ambiental (Universidade Federal do Paraná) e gerente da Catena Planejamento Territorial. Email: glauco@catenaterritorial.com 
ANEXO 1 - Estudos de viabilidade do Cenário 1

\begin{tabular}{|c|c|c|c|c|c|c|c|c|c|c|c|}
\hline \multicolumn{12}{|c|}{ Cenário 1 - Projeto biometano com granja Progresso e Conquista } \\
\hline Ano & Zero & 1 & 2 & 3 & 4 & 5 & 6 & 7 & 8 & 9 & 10 \\
\hline Entrada & $\mathbf{R} \$$ & \begin{tabular}{l|l|}
$R \$ 50.510,16$ \\
\end{tabular} & $\mathrm{R} \$ 50.510,16$ & $\mathrm{R} \$ \mathbf{5 0 . 5 1 0 , 1 6}$ & $\mathrm{R} \$ \mathbf{5 0 . 5 1 0 , 1 6}$ & $\mathrm{R} \$ 50.510,16$ & $\mathrm{R} \$ 50.510,16$ & $\mathrm{R} \$ \mathbf{5 0 . 5 1 0 , 1 6}$ & $\mathrm{R} \$ 50.510,16$ & $\mathrm{R} \$ \mathbf{5 0 . 5 1 0 , 1 6}$ & $\mathrm{R} \$ 221.277,49$ \\
\hline Receita Biometano & & \begin{tabular}{ll|}
$\mathrm{R} \$ 50.510,16$ \\
\end{tabular} & $\mathrm{R} \$ 50.510,16$ & $\mathrm{R} \$ 50.510,16$ & $\mathrm{R} \$ 50.510,16$ & $\mathrm{R} \$ 50.510,16$ & $\mathrm{R} \$ 50.510,16$ & $R \$ 50.510,16$ & $\mathrm{R} \$ 50.510,16$ & $\mathrm{R} \$ 50.510,16$ & 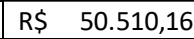 \\
\hline Transporte e armazenamento de gás & & & & & & & & & & & $R \$ 100.767,33$ \\
\hline \begin{tabular}{|l|} 
Microposto \\
\end{tabular} & & & & & & & & & & & R\$ $70.000,00$ \\
\hline Conversão veículos & & & & & & & & & & & \begin{tabular}{|l|l} 
& $37.333,33$ \\
\end{tabular} \\
\hline Saída & R\$ 445.930,00 & RȘ $10.862,40$ & $R \$ 10.862,40$ & $\mathrm{R} \$ \mathbf{1 0 . 8 6 2 , 4 0}$ & $\mathrm{R} \$ \mathbf{1 0 . 8 6 2 , 4 0}$ & $\mathrm{R} \$ 10.862,40$ & $\mathrm{R} \$ 10.862,40$ & RS\$ 10.862,40 & $\mathrm{R} \$ \mathbf{1 0 . 8 6 2 , 4 0}$ & $\mathrm{R} \$ 10.862,40$ & \begin{tabular}{|l|l|}
$\mathrm{R} \$$ & $10.862,40$ \\
\end{tabular} \\
\hline Despesas operacionais (manutenção dos & & RS $10.862,40$ & $R \$ 10.862,40$ & $\mathrm{R} \$ 10.862,40$ & $R \$ 10.862,40$ & $\mathrm{R} \$ 10.862,40$ & $R \$ 10.862,40$ & R\$ 10.862,40 & $\mathrm{R} \$ \mathbf{1 0 . 8 6 2 , 4 0}$ & $\mathrm{R} \$ 10.862,40$ & \begin{tabular}{|l|l|}
$R \$$ & $10.862,40$ \\
\end{tabular} \\
\hline Transporte e armazenamento de gás & $\mathrm{R} \$ 215.930,00$ & & & & & & & & & & \\
\hline Microposto & $R \$ 150.000,00$ & & & & & & & & & & \\
\hline Conversão veículos & \begin{tabular}{|l|l|}
$R S$ & $80.000,00$ \\
\end{tabular} & & & & & & & & & & \\
\hline \begin{tabular}{|l|} 
Fluxo líquido \\
\end{tabular} & $-\mathrm{R} \$ 445.930,00$ & $\mathrm{R} \$ 39.647,76$ & $R \$ 39.647,76$ & $\mathrm{R} \$ 39.647,76$ & $\mathrm{R} \$ 39.647,76$ & $R \$ 39.647,76$ & $\mathrm{R} \$ 39.647,76$ & $\mathrm{R} \$ 39.647,76$ & $\mathrm{R} \$ 39.647,76$ & $R \$ 39.647,76$ & $R \$ 210.415,09$ \\
\hline
\end{tabular}

Informe GEPEC, ISSN:1679-415X, Toledo, v. 25, n.1, p. 185-202, jan./jun. 2021. 
ANEXO 2 - Estudos de viabilidade do Cenário 2

\begin{tabular}{|c|c|c|c|c|c|c|c|c|c|c|c|c|c|c|c|c|c|c|c|}
\hline \multicolumn{20}{|c|}{ Cenário 2 - Projeto biometano com granja Progresso } \\
\hline Ano & & Zero & & 1 & 2 & 3 & & 4 & & 5 & & 6 & & 7 & & 8 & & 9 & 10 \\
\hline Entrada & $\mathbf{R} \$$ & - & $\mathbf{R} \$$ & $50.510,16$ & $\mathrm{R} \$ 50.510,16$ & $\mathrm{R} \$ 50.510,16$ & $\mathbf{R} \mathbf{S}$ & $50.510,16$ & $\mathbf{R} \$$ & $50.510,16$ & $\mathbf{R} \$$ & $50.510,16$ & $\mathbf{R} \$$ & $50.510,16$ & $\mathbf{R} \$$ & $50.510,16$ & $\mathbf{R} \$$ & $50.510,16$ & $\mathrm{R} \$ 189.033,16$ \\
\hline Receita Biometano & & & $\mathrm{RS}$ & $50.510,16$ & $\mathrm{R} \$ 50.510,16$ & $\mathrm{R} \$ 50.510,16$ & $\mathrm{RS}$ & $50.510,16$ & $\mathrm{R} \$$ & $50.510,16$ & $\mathrm{RS}$ & $50.510,16$ & $\mathrm{RS}$ & $50.510,16$ & $\mathrm{R} \$$ & $50.510,16$ & $\mathrm{RS}$ & $50.510,16$ & $\mathrm{R} \$ \quad 50.510,16$ \\
\hline Transporte e armazenamento de gás & & & & & & & & & & & & & & & & & & & $R \$ \quad 68.523,00$ \\
\hline Microposto & & & & & & & & & & & & & & & & & & & $\mathrm{R} \$ \quad 70.000,00$ \\
\hline Conversão veículos & & & & & & & & & & & & & & & & & & & $\mathrm{R} \$ \mathbf{3} \quad 37.333,33$ \\
\hline Saída & RS & $376.835,00$ & $\mathbf{R} \mathbf{S}$ & $10.862,40$ & $\mathrm{R} \$ \mathbf{1 0 . 8 6 2 , 4 0}$ & $\mathrm{R} \$ 10.862,40$ & $\mathbf{R} \mathbf{S}$ & $10.862,40$ & $\mathbf{R} \mathbf{S}$ & $10.862,40$ & $\mathrm{RS}$ & $10.862,40$ & $\mathbf{R} \mathbf{S}$ & $10.862,40$ & $\mathbf{R} \mathbf{S}$ & $10.862,40$ & $\mathbf{R} \mathbf{S}$ & $10.862,40$ & $\mathrm{R} \$ \quad 10.862,40$ \\
\hline Despesas operacionais (manutenção dos & & & $\mathrm{R} \$$ & $10.862,40$ & $\mathrm{R} \$ 10.862,40$ & $\mathrm{R} \$ 10.862,40$ & $\mathrm{R} \$$ & $10.862,40$ & $\mathrm{RS}$ & $10.862,40$ & $\mathrm{R} \$$ & $10.862,40$ & $\mathrm{R} \$$ & $10.862,40$ & $\mathrm{R} \$$ & $10.862,40$ & $\mathrm{R} \$$ & $10.862,40$ & $\mathrm{R} \$ \quad 10.862,40$ \\
\hline Transporte e armazenamento de gás & $\mathrm{R} \$$ & $146.835,00$ & & & & & & & & & & & & & & & & & \\
\hline Microposto & $\mathrm{R} \$$ & $150.000,00$ & & & & & & & & & & & & & & & & & \\
\hline Conversão veículos & $\mathrm{RST}$ & $80.000,00$ & & & & & & & & & & & & & & & & & \\
\hline Fluxo líquido & -RȘ & $376.835,00$ & $\mathbf{R} \mathbf{S}$ & $39.647,76$ & $\mathrm{R} \$ 39.647,76$ & $\mathrm{R} \$ 39.647,76$ & $\mathbf{R} \mathbf{S}$ & $39.647,76$ & $\mathbf{R} \mathbf{S}$ & $39.647,76$ & $\mathrm{R} \$$ & $39.647,76$ & $\mathrm{RS}$ & $39.647,76$ & RȘ & $39.647,76$ & $\mathbf{R} \mathbf{S}$ & $39.647,76$ & $\mathrm{R} \$ 178.170,76$ \\
\hline
\end{tabular}


ANEXO 3 - Estudos de viabilidade do Cenário 3

\begin{tabular}{|c|c|c|c|c|c|c|c|c|c|c|c|}
\hline \multicolumn{12}{|c|}{ Cenário 3 - Projeto biometano granja Conquista } \\
\hline Ano & Zero & 1 & 2 & 3 & 4 & 5 & 6 & 7 & 8 & 9 & 10 \\
\hline Entrada & $\mathbf{R} \$$ & $\mathrm{R} \$ 50.510,16$ & $\mathrm{R} \$ \mathbf{5 0 . 5 1 0 , 1 6}$ & $\mathrm{R} \$ 50.510,16$ & $\mathrm{R} \$ 50.510,16$ & $\mathbf{R} \$ \mathbf{5 0 . 5 1 0 , 1 6}$ & $\mathrm{R} \$ \mathbf{5 0 . 5 1 0 , 1 6}$ & $\mathrm{R} \$ 50.510,16$ & $\mathrm{R} \$ 50.510,16$ & $\mathrm{R} \$ 50.510,16$ & $\mathbf{R} \$ 123.907,49$ \\
\hline Receita Biometano & & $\mathrm{R} \$ \quad 50.510,16$ & $\mathrm{R} \$ 50.510,16$ & $\mathrm{R} \$ 50.510,16$ & $\mathrm{R} \$ 50.510,16$ & $\mathrm{R} \$ 50.510,16$ & $\mathrm{R} \$ \mathbf{5 0 . 5 1 0 , 1 6}$ & $\mathrm{R} \$ \mathbf{5 0 . 5 1 0 , 1 6}$ & $\mathrm{R} \$ 50.510,16$ & $\mathrm{R} \$ 50.510,16$ & $\mathrm{RS} \quad 50.510,16$ \\
\hline Transporte e armazenamento de gás & & & & & & & & & & & $\begin{array}{ll}\mathrm{R} & 3.397,33 \\
\end{array}$ \\
\hline Microposto & & & & & & & & & & & $\mathrm{R} \$ \mathbf{7} \quad 70.000,00$ \\
\hline Conversão veículos & & & & & & & & & & & $\mathrm{R} \$ \mathbf{3} \quad 37.333,33$ \\
\hline Saída & \begin{tabular}{|l}
$\mathrm{R} \$ 237.280,00$ \\
\end{tabular} & $\mathrm{R} \$ \mathbf{S} \quad 10.862,40$ & $\mathrm{R} \$ \mathbf{1 0 . 8 6 2 , 4 0}$ & $\mathrm{R} \$ 10.862,40$ & $\mathrm{R} \$ \mathbf{1 0 . 8 6 2 , 4 0}$ & $\mathrm{R} \$ \mathbf{1 0 . 8 6 2 , 4 0}$ & $\mathrm{R} \$ \mathbf{1 0} 10.862,40$ & $R \$ 10.862,40$ & $\mathrm{R} \$ \mathbf{1 0 . 8 6 2 , 4 0}$ & $\mathrm{R} \$ 10.862,40$ & 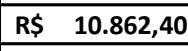 \\
\hline $\begin{array}{l}\text { Despesas operacionais (manutenção dos } \\
\text { equipamentos do sistema) }\end{array}$ & & $\mathrm{R} \$ \quad 10.862,40$ & $\mathrm{R} \$ 10.862,40$ & $\mathrm{R} \$ 10.862,40$ & $\mathrm{R} \$ 10.862,40$ & $\mathrm{R} \$ 10.862,40$ & $\mathrm{R} \$ 10.862,40$ & $\mathrm{R} \$ 10.862,40$ & $\mathrm{R} \$ 10.862,40$ & $\mathrm{R} \$ 10.862,40$ & $\mathrm{R} \$ \quad 10.862,40$ \\
\hline Transporte e armazenamento de gás & $\mathrm{R} \$ \quad 7.280,00$ & & & & & & & & & & \\
\hline Microposto & $\mathrm{R} \$ 150.000,00$ & & & & & & & & & & \\
\hline Conversão veículos & $\mathrm{R} \$ \quad 80.000,00$ & & & & & & & & & & \\
\hline Fluxo líquido & $-\mathrm{R} \$ \mathbf{2 3 7 . 2 8 0 , 0 0}$ & $\mathrm{R} \$ \mathbf{3} \quad 39.647,76$ & $\mathrm{R} \$ \mathbf{3 9 . 6 4 7 , 7 6}$ & $R \$ 39.647,76$ & $\mathrm{R} \$ \mathbf{3 9 . 6 4 7 , 7 6}$ & $\mathrm{R} \$ \mathbf{3 9 . 6 4 7 , 7 6}$ & $\mathrm{R} \$ \mathbf{3 9 . 6 4 7 , 7 6}$ & $\mathrm{R} \$ \mathbf{3 9 . 6 4 7 , 7 6}$ & $\mathrm{R} \$ 39.647,76$ & $R \$ 39.647,76$ & $\mathrm{R} \$ \mathbf{1 1 3 . 0 4 5 , 0 9}$ \\
\hline
\end{tabular}

Informe GEPEC, ISSN:1679-415X, Toledo, v. 25, n.1, p. 185-202, jan./jun. 2021. 